\title{
Efficacy of Surgical Tissue Glues and Supporters for Treatment of Prolonged Air Leaks in Bullous Emphysema
}

\author{
Erkan Akar1, Miktat Arif Haberal1, Ozlem Sengören Dikis² \\ Department of Thoracic Surgeryl / Pulmonary Diseases ${ }^{2}$, Health Sciences University, Bursa Yuksek Ihtisas Training and Research Hospital, \\ Bursa, Turkey
}

\begin{abstract}
Objective: To investigate the effect of collagen matrix tissue supporter made of bovine pericardium and polyethylene glycol (PEG) tissue glue on prolonged air leak and postoperative complications in patients with bullous emphysema.

Study Design: A retrospective study.

Place and Duration of Study: Department of Thoracic Surgery, Health Sciences University, Bursa Yuksek Ihtisas Training and Research Hospital, Bursa, Turkey, from January 2010 to December 2018.

Methodology: A total of 60 patients (57 males, 3 females) with radiologically confirmed bullous emphysema, who underwent surgery for secondary spontaneous pneumothorax were reviewed, and grouped into three: Group 1 underwent endostapler/ peristrips (20 patients); Group 2 underwent endostapler / coseal (18 patients), and Group 3 underwent endostapler/ peristrips / coseal (22 patients). All groups underwent video-assisted thoracoscopic surgery. The groups were compared for complications, time for removal of chest tube, and duration of hospital stay.

Results: The groups were similar with respect to age and gender. The mean time to chest tube removal was $7.57 \pm 4.73$ days (range; 3-21 days); the mean duration of hospital stay was $9.23 \pm 5.00$ days (range; 4-23 days). Group 3 had the shortest time to chest tube removal and duration of hospital stay (5.82 \pm 2.87 and $7.36 \pm 3.04 ; p=0.010$ and $p=0.006$ ). Significant inter-group difference originated between Group 2 and Group $3(p=0.008$ and $p=0.005)$. Group 2 had the longest time to chest tube removal and duration of hospital stay (10.22 \pm 5.11 and $12.22 \pm 5.36)$. Group 3 had significantly a lower rate of prolonged air leak $(9.1 \% \mathrm{n}=1 ; \mathrm{p}=0.021)$.

Conclusion: Using coseal with a tissue supporter like Peristrips reduces postoperative complications, time to chest tube removal, and duration of hospital stay compared to its stand alone use.
\end{abstract}

Key Words: Bullous emphysema, Pneumothorax, Polyethylene glycol, Bovine pericardium.

How to cite this article: Akar E, Haberal MA, Dikis OS. Efficacy of surgical tissue glues and supporters for treatment of prolonged air leaks in bullous emphysema. J Coll Physicians Surg Pak 2020; 30(1):57-61.

\section{INTRODUCTION}

Bullous lung diseases are still disputable with respect to their definition, classification, and treatment algorithm. New approaches have been put forth especially for treatment in recent years. Prognosis is closely linked to patient selection for surgery, applied treatment methods, and surgeon's experience. Prolonged air leak is a primary problem in surgery. ${ }^{1}$

Many techniques and equipment are used to prevent this condition. In the present study the aim was to investigate surgical treatment outcomes in bullous lung disorders complicated by pneumothorax and the effect of collagen matrix tissue supporter made of bovine pericardium and polyethylene glycol (PEG) tissue glue on prolonged air leak and complications in patients with

Correspondence to: Erkan Akar, Department of Thoracic Surgery, Health Sciences University, Bursa Yuksek Ihtisas Training and Research Hospital, Bursa, Turkey

E-mail:drerkanakar@hotmail.com

Received: July 23, 2019; Revised: Novermber 16, 2019;

Accepted: December 16, 2019 bullous emphysema leading to secondary spontaneous pneumothorax (SSP).

\section{METHODOLOGY}

The medical records of 179 patients with SSP from January 2010 to December 2018 were retrospectively reviewed. Sixty patients with radiologically confirmed bullous emphysema, who underwent surgery, were enrolled. Nineteen patients, who were treated with tube thoracostomy, thoracentesis, or nasal oxygen alone, were excluded. The patients were randomly selected in terms of age and gender, regardless of bullous emphysema and lung parenchyma. The patients were grouped into three groups: Group 1 included 20 patients that underwent wedge resection with an endostapler supported by Peristrips made of bovine pericardium; Group 2 contained 18 patients that were applied Coseal tissue glue at the suture line after being operated with wedge resection with endostapler. Group 3 contained 22 patients that were applied Coseal tissue glue to the stapler line after being operated with wedge resection while the endostapler line was supported by Peristrips. Considering that persisting air leak from chest tube and 
pain due to chest tube may affect outcomes, no preoperative respiratory function test was performed. Preoperative pulmonary function test and respiratory physiotherapy could not be performed in COPD patients with air leak and chest tube. Bronchodilators, oxygen therapy, antibiotherapy and mucolytic therapy were applied to these patients. These patients were consulted to the cardiology and chest diseases departments. The surgical treatment indications were recurrent pneumothorax and prolonged air leak. The groups were formed irrespective of the extensiveness and the status of lung parenchyma. The groups were compared with respect to age, gender, treatment outcomes, occurrence of complications, time to removal of chest tube, and duration of hospital stay.

The study was approved by the local ethics and clinical research committee of the hospital (2011-KAEK-25 2019/06-22). All participants provided written informed consents.

All patients were intubated with a double lumen endotracheal tube and placed in lateral decubitus position under general anesthesia. The first port to be used for camera was placed to the seventh intercostal space on the midaxillary line. After the pleural space and lung surface was inspected for possible bullous structures, two additional incisions were made to the fourth intercostal space on the anterior axillary line and eighth intercostal space on the midscapular line. Although these incision sites were used in most cases, port sites were modified in accordance with bulla's location. When there were adhesions between the two pleural layers, they were freed with blunt and sharp dissections. Bulla/bullae detected in lung parenchyma were treated with endoscopic stapler (Endo-GIA 45-60, $4.8 \mathrm{~mm}$, Auto Suture Company, United States Surgical Corp, Norwalk, CT), Peristrips tissue supporter and Coseal tissue glue at the suture line. As an additional procedure, mechanical abrasion was carried out on parietal pleura in the apical region (prolene mesh). A 28/32 F chest tube was placed to the apex and the procedure was terminated.

Study data were analysed using IBM SPSS version 25.0 software package for Windows (IBM Corporation, Armonk, New York, USA). The data were expressed as number, percent, mean and standard deviation. Intergroup comparisons were performed using Chi-Square (Fisher's Exact test as needed), one-way ANOVA, and post-hoc Tukey tests; $p<0.05$ was considered statistically significant.

\section{RESULTS}

This study involved a total of 60 patients with SSP, of which 57 (95\%) were males. The mean age was 52.35 \pm 15.65 years (range, 25-83). Group 1 contained 20 patients (20 males); Group 2 contained 18 patients (16 males, 2 females); and Group 3 contained 22 patients (21 males, 1 female). The three groups were statistically similar with respect to age and sex distribution. The mean time to chest tube removal was $7.57 \pm 4.73$ days (range; 3-21 days); the mean duration of hospital stay was $9.23 \pm 5.00$ days (range; $4-23$ days, Table I). The time to chest tube removal and duration of hospital stay were significantly shorter in Group 3 (5.82 \pm 2.87 and $7.36 \pm 3.04$ days; $p=0.010$ and $p=0.006$ ). The significance of difference was derived from the difference between Group 2 and Group $3(p=0.008$ and $p=0.005)$ (Figure 1). Group 2 had the longest time to chest tube removal and duration of hospital stay $(10.22 \pm 5.11$ and $12.22 \pm 5.36)$. Among postoperative complications, prolonged air leak occurred in 11 (18.3\%) patients; recurrent pneumothorax in $4(6.7 \%)$ patients; empyema in $1(1.7 \%)$ patient; and wound infection in $2(3.3 \%)$ patients. Group 3 had a significantly lower rate of prolonged air leak compared to the other groups $(9.1 \% n=1 ; p=0.021$, Table II). Group 2 had the highest, albeit statistically non-significant rate of complications. As compared to Group 2, Group 1 had both shorter time to chest tube removal and duration of hospital stay as well as a lower rate of complications (7.10 \pm 5.14 vs. $8.60 \pm 5.35)$. The overall mean follow-up time was 36 months, and no death occurred.

\section{DISCUSSION}

The aim of the surgical treatment of spontaneous pneumothorax is to prevent recurrences by achieving lung re-expansion as soon and as much as possible. Inadequate treatment of pneumothorax, especially in patients with bullous lung results in higher mortality and morbidity. ${ }^{1}$ Air leak is an important problem at postoperative period in these patients. ${ }^{2}$

In patients with SSP, the degree of lung injury is important. As prolonged air leak is the main cause of prolonged hospital stay after lung resection, high-risk patients should be carefully evaluated prior to surgery. The risk of prolonged air leak is high in patients with a forced expiratory volume in one second (FEV 1) and a diffusion capacity of $<50 \%$ and those with diffuse bullous pathology or generalised emphysema on thorax CT.

Surgical techniques and procedures should be performed with care; and full expansion of the remaining lung should be achieved. In recent years, a number of bronchoscopic treatment methods have been developed for volume reduction. These include endobronchial blockers, respiratory tract bypass, endobronchial valves, steam ablation, and respiratory tract implants. Although the use of these different techniques have been reported in the literature, their efficacy is unclear with the available information.2,3 Therefore, surgery is inevitable in complicated bullous lung disease. Hence, we included solely patients with diffuse emphysema, who developed pneumothorax due to bulla rupture. One of the success 
Table I: Distribution of time to tube removal and duration of hospital stay.

\begin{tabular}{|c|c|c|c|c|c|c|c|c|c|}
\hline & \multicolumn{7}{|c|}{$95 \% \mathrm{Cl}$} & \multirow[b]{2}{*}{$\mathrm{F}$} & \multirow[b]{2}{*}{$\mathrm{p}^{*}$} \\
\hline & $\mathrm{n}$ & Mean & SD & Lower & Upper & Min. & Max. & & \\
\hline Time to tube removal & & & & & & & & 5.043 & 0.010 \\
\hline Group 1 & 20 & 7.10 & 5.14 & 4.69 & 9.51 & 3 & 21 & & \\
\hline Group 2 & 18 & 10.22 & 5.11 & 7.68 & 12.77 & 4 & 19 & & \\
\hline Group 3 & 22 & 5.82 & 2.87 & 4.54 & 7.09 & 3 & 16 & & \\
\hline Total & 60 & 7.57 & 4.73 & 6.34 & 8.79 & 3 & 21 & & \\
\hline Duration of hospital stay & & & & & & & & 5.698 & 0.006 \\
\hline Group 1 & 20 & 8.60 & 5.35 & 6.09 & 11.11 & 4 & 23 & & \\
\hline Group 2 & 18 & 12.22 & 5.36 & 9.55 & 14.89 & 6 & 22 & & \\
\hline Group 3 & 22 & 7.36 & 3.04 & 6.01 & 8.72 & 4 & 18 & & \\
\hline Total & 60 & 9.23 & 5.00 & 7.94 & 10.52 & 4 & 23 & & \\
\hline
\end{tabular}

$S D=S t a n d a r d$ deviation, $\mathrm{Cl}=$ Confidence interval, Min=Minimum, Max=Maximum, ${ }^{*}$ One-way ANOVA.

Table II: Comparison of study groups with respect to postoperative complications.

\begin{tabular}{|c|c|c|c|c|c|c|c|c|}
\hline & \multicolumn{2}{|c|}{ Group 1} & \multicolumn{2}{|c|}{ Group 2} & \multicolumn{2}{|c|}{ Group 3} & \multirow[b]{2}{*}{ Chi-Square } & \multirow[b]{2}{*}{$p^{*}$} \\
\hline & $\mathrm{n}$ & $\%$ & $\mathrm{n}$ & $\%$ & $\mathrm{n}$ & $\%$ & & \\
\hline \multicolumn{9}{|c|}{ Prolonged air leak } \\
\hline No & 17 & 34.7 & 11 & 22.4 & 21 & 42.9 & 7.364 & 0.021 \\
\hline Yes & 3 & 27.3 & 7 & 63.6 & 1 & 9.1 & & \\
\hline \multicolumn{9}{|c|}{ Recurrent pnuemothorax } \\
\hline No & 19 & 33.9 & 15 & 26.8 & 22 & 39.3 & 3.79 & 0.065 \\
\hline Yes & 1 & 25,0 & 3 & 75.0 & 0 & 0.0 & & \\
\hline \multicolumn{9}{|c|}{ Emphysema } \\
\hline No & 20 & 33.9 & 17 & 28.8 & 22 & 37.3 & 2.072 & 0.300 \\
\hline Yes & 0 & 0,0 & 1 & 100.0 & 0 & 0.0 & & \\
\hline \multicolumn{9}{|c|}{ Wound infection } \\
\hline No & 20 & 34.5 & 18 & 31.0 & 20 & 34.5 & 2.384 & 0.324 \\
\hline Yes & 0 & 0,0 & 0 & 0.0 & 2 & 100.0 & & \\
\hline
\end{tabular}

*Fisher's Exact test.

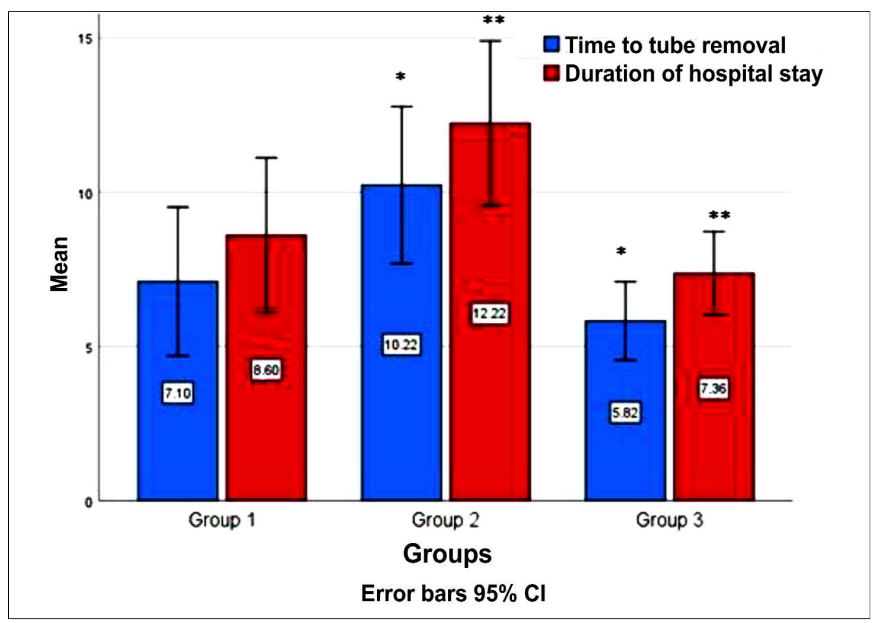

Figure 1: Comparison of the study groups with regard to time to tube removal and duration of hospital stay.

*Post-hoc Tukey $p=0.008$; **Post-hoc Tukey $p=0.005$.

criteria of thoracic surgery is the complete expansion of the lung. For this reason pleural abrasion, various chemical agents (such as talc) and pleural tent reduction can be performed on the lung during surgery. After performing these procedures, the lung may not be expanded and pleural space may remain. If the remaining pleural space is less than 2, according to the re-expansion index, the patient's chest tube is clamped one day in advance; and the chest X-ray taken the next day is checked for the condition of the lung. If the lung does not collapse and the radiographic image of the lung parenchyma is at the same level, the chest tube can be removed and aseptic space can be left. In our study, no aseptic space was left in any patient.

VATS approach is routinely used, and the first option for bullous lung surgery. This condition has been identified with wedge resection for bullectomy. The main postoperative problem is prolonged air leak, which is seen in $22 \%$ of patients with emphysema. 4 This study showed a prolonged air leak rate of $18.3 \%$, which was lower than figures reported in the literature.

Despite the development of novel techniques, patients with SSP may develop prolonged air leak, recurrent pneumothorax, and postoperative pneumonia after bulla excision. Persistent air leaks may cause death, especially in patients with respiratory failure and severe infections accompanying SSP. Therefore, air leak should be properly managed.5-7

Prolonged air leak, the most common cause of morbidity in chest surgery, should be managed with different strategies. The use of tissue glues has been shown to lower the rates of pneumothorax, secondary infection, and prolonged air leaks. ${ }^{8}$ Among postoperative compli- 
cations, our study demonstrated prolonged air leak in 11 $(18.3 \%)$ cases, recurrent pneumothorax in $4(6.7 \%)$ cases, empyema in $1(1.7 \%)$ case, and wound infection in $2(3.3 \%)$ cases; but none of the patients died.

As part of attempts for preventing or reducing alveolar air leaks I, autologous blood patches, collagen matrix supporters made of bovine pericardium or synthetic materials, glutaraldehyde, or PEG-based synthetic surgical tissue glues have been developed. Surgical tissue glues have been recommended to be used in cases where prolonged air leak cannot be controlled by stapler alone. Former studies have focused on Coseal, a biologically compatible PEG polymer, among available surgical tissue glues. Coseal is composed of two synthetic PEGs: a diluted hydrogen chloride solution and a sodium phosphate/carbonate solution. During its application, the solutions merge to form a hydrogel that cross-links proteins and causes instant tissue adhesion. The sealer is completely absorbed by the body within 30 days of application. 9,10

The main goal of supporting the surgical stapler line with biomaterials is to sustain tissue viability at the resection border and to prevent air leak. A support material should be flexible and thin enough to slide into a stapler and to be cut easily. Furthermore, it should be pressureresistant and not allow air leak. 11,12

Federico et al. reported that Coseal reduced the rate of air leaks and duration of hospital stay. The material was easy-to-use and caused no morbidity. ${ }^{13}$ However, despite having been reduced, air leaks were still present in a small patient group and persisted for more than 2 days in $2(8 \%)$ of those patients. The authors concluded that using that surgical tissue glue in selected cases may contribute to a lowered complication rate.

D'Andrilli et al. in a 203-patient study, formed an incomplete fissure by supporting the stapler line with a collagen matrix made of bovine pericardium. ${ }^{14}$ They also applied Coseal to the stapler line to investigate its efficacy and safety. They formed two groups and in the Coseal group they used surgical tissue glue in the stapler line. Coseal was significantly effective for reducing air leaks intraoperatively and within 24-48 hours postoperatively. Although it reduced the durations of hospital stay and prolonged air leak, no statistical significance was observed. 10

Three randomised studies tested the efficacy of synthetic bio-absorbable (PEG-based) tissue glue. They showed significant reductions in times to chest tube removal and duration of hospital stay and significant lowering in the rate of prolonged air leak. ${ }^{15-17}$

Belda-Sanchís et al. reported that surgical tissue glues were effective at postoperative air leak. However, they found no sign of reduced duration of hospital stay. ${ }^{18}$ Lang et al. demonstrated that tissue supporters reduced the time of air leaks. Our study also showed better results with Peristrip use. 19

Based on positive results obtained in emphysema surgery, supporting the stapler line with synthetic or biological materials has been proposed.12,20 Likewise, the present study investigated the efficacy of Peristrips made of bovine pericardium and Coseal used to support the stapler line on air leak and complications in emphysema patients. In Group 1, where Peristrips alone was used, times to discharge and tube removal were better compared to Group 2, where no Peristrips was used. Laquaglie et al. in a 216-case series, studied cost, hospital stay, and effects on air leak prevention pertaining to Coseal. ${ }^{10}$ The patients were divided into two groups; in the Coseal group air leak, prolonged air leak, and duration of hospital stay were significantly reduced. Venuta et al. used Coseal to prevent air leaks in 50 cases undergoing lung resection in case of incomplete fissure. ${ }^{20}$ Compared to the control group, the Coseal group had a lower rate of prolonged air leak.

The authors concluded that Coseal may be used for reducing the rate of air leaks in selected cases. In contrast to the above-mentioned articles, it is found longer times to chest tube removal and discharge and a higher rate of complications in Group 2, where Coseal alone was used. Nevertheless, it was statistically proven that results were better in Group 3, where it was used in conjunction with Peristrips.

\section{CONCLUSION}

Stapler's technological advancement coupled with the combined use of Peristrips tissue supporter made of bovine pericardium and Coseal surgical tissue glue in minimally invasive endoscopic methods for effective treatment of prolonged air leak, leads to reduced postoperative complication rates and more pronounced clinical benefits the patients may obtain from surgery.

\section{ETHICAL APPROVAL:}

This study has been approved by the Ethics Committee of the Health Sciences University, Bursa Yuksek Ihtisas Training and Research Hospital, Bursa, Turkey.

\section{PATIENTS' CONSENT:}

All participants provided written informed consents.

\section{CONFLICT OF INTEREST:}

Authors declared no conflict of interest.

\section{AUTHORS' CONTRIBUTION:}

EA: Conception of the manuscript, study design, patients' follow-up, data collection, statistical analysis, manuscript writing and revision.

$\mathrm{MAH}$ : Study design, patients' follow-up and manuscript revision.

OSD: Study design, patients' follow-up and data collection. 


\section{REFERENCES}

1. Caviezel C. Lung volume reduction surgery in selected patients with severe emphysema significant benefit with low peri operative risk. J Xiangya Med 2017; 2:48.

2. Drahush N, Miller AD, Smith JS, Royer AM, Spiva M. Standardized approach to prolonged air leak reduction after pulmonary resection. Ann Thorac Surg 2016; 101:2097-101.

3. You B, Zhao $\mathrm{Y}$, Hou S, Hu B, Li H. Lung volume reduction surgery in hypercapnic patients: A single-center experience from China. J Thorac Dis 2018; 10(Suppl 23):S2698-S2703.

4. Burt BM, Kosinski AS, Shrager JB, Onaitis MW, Weigel T. Thoracoscopic lobectomy is associated with acceptable morbidity and mortality in patients with predicted postoperative forced expiratory volume in 1 second or diffusing capacity for carbon monoxide less than $40 \%$ of normal. Thorac Cardiovasc Surg 2014; 148:19-28.

5. Kiss G, Claret A, Desbordes J, Porte H. Thoracic epidural anaesthesia for awake thoracic surgery in severely dyspnoeic patients excluded from general anaesthesia. Interact Cardiovasc Thorac Surg 2014; 19:816-23.

6. Delpy JP, Pagès PB, Mordant P, Falcoz PE, Thomas $P$, Le Pimpec-Barthes $F$, et al. Surgical management of spontaneous pneumothorax: Are there any prognostic factors influencing postoperative complications. Eur J Cardiothorac Surg 2016; 49:862-7.

7. Lee SC, Lee DH. Influence of old pulmonary tuberculosis on the management of secondary spontaneous pneumothorax in patients over the age of 70 years. J Thorac Dis 2016; 8:2903-10.

8. Petsas T, Siamblis D, Giannakenas C, Tepetes K, Dougenis D, Spiropoulos $\mathrm{K}$, et al. Fibrin glue for sealing the needle track in fine-needle percutaneous lung biopsy using a coaxial system part II clinical study. Cardiovasc Intervent Radiol 1995; 18:378-82.

9. Baxter Healthcare D: CoSeal package insert. IL 2006. Availiable at http://www. baxter.com/downloads/healthcare_professionals/ products/CoSeal_PI.pdf.

10. Lequaglie C, Giudice G, Marasco R, Morte AD, Gallo M. Use of a sealant to prevent prolonged air leaks after lung resection: $A$ prospective randomized study. J Cardiothorac Surg 2012; 7:106.
11. Milenkovic B, Janjic S-D, Popevic S. Review of lung sealant technologies for lung volume reduction in pulmonary disease. Med Devices (Auckl) 2018; 11:225-31.

12. Kumbasar U, Yilmaz Y, Özercan MM, Ancin B, Dikmen E, Dogan $R$. The effect of fibrin sealant spraying on prolonged air leak after pulmonary resections: A single center experience. Curr Thorac Surg 2017; 2:81-4.

13. Venuta F, Diso D, De Giacomo T, Anile M, Rendina EA, Coloni GF. Use of a polymeric sealant to reduce air leaks after lobectomy. J Thorac Cardiovasc Surg 2006; 132:422-3.

14. D'Andrilli A, Andreetti C, Ibrahim M, Ciccone AM, Venuta F, Mansmann $U$, et al. A prospective randomized study to assess the efficacy of a surgical sealant to treat air leaks in lung surgery. Eur J Cardiothorac Surg 2009; 35:817-20.

15. Porte HL, Jany T, Akkad R, Conti M, Gillet PA, Guidat A, et al. Randomized controlled trial of a synthetic sealant for preventing alveolar air leaks after lobectomy. Ann Thorac Surg 2001; 71:1618-22.

16. McGuire LA, Yee J. Clinical outcomes of polymeric sealant use in pulmonary resection: A systematic review and meta-analysis of randomized controlled trials. J Thorac Dis 2018; 10(Suppl 32): S3728-39.

17. Ito $\mathrm{H}$, Nakayama $\mathrm{H}$. The efficiency and safety of variable-height staple technology in pulmonary resections. Clin Surg 2018; 3: 2091.

18. Belda Sanchís J, Serra Mitjans M, Iglesias Sentis M, Rami R. Surgical sealant for preventing air leaks after pulmonary resections in patients with lung cancer. Cochrane Database Syst Rev 2010; 1:CD003051.

19. Lang G, Csekeö A, Stamatis G, Lampl L, Hagman L, Marta GM, et al. Efficacy and safety of topical application of human fibrinogen/thrombin-coated collagen patch (TachoComb) for treatment of air leakage after standard lobectomy. Eur $J$ Cardiothorac Surg 2004; 25:160-6.

20. Venuta F, Rendina EA, De Giacomo T, Flaishman I, Guarino E, Ciccone AM, et al. Technique to reduce air leaks after pulmonary lobectomy. Eur J Cardiothorac Surg 1998; 13:361-4. 